\author{
Jung-Min Koh $\cdot$ Bermseok Oh $\cdot$ Jong Yong Lee \\ Jong-Keuk Lee · Kuchan Kimm · Ghi Su Kim \\ Byung Lae Park · Hyun Sub Cheong \\ Hyoung Doo Shin · Jung Min Hong · Tae-Ho Kim \\ Eui Kyun Park · Shin-Yoon Kim
}

\title{
Association study of semaphorin 7a (sema7a) polymorphisms with bone mineral density and fracture risk in postmenopausal Korean women
}

Received: 5 September 2005/ Accepted: 11 October 2005 / Published online: 22 December 2005

(C) The Japan Society of Human Genetics and Springer-Verlag 2005

\begin{abstract}
Bone mineral density (BMD), the major factor determining bone strength, is closely related to osteoporotic fracture risk and is determined largely by multiple genetic factors. Semaphorin 7a (SEMA7A), a recently described member of the semaphorin family, has been shown to play a critical role in the activation of monocyte/macrophages that share progenitors with bone-resorbing osteoclasts and thus might contribute to osteoclast development. In the present study, we directly sequenced the SEMA7A gene in 24 Korean individuals, and identified 15 sequence variants.
\end{abstract}

Electronic Supplementary Material Supplementary material is available for this article at http://dx.doi.org/10.1007/s10038-005$0331-\mathrm{z}$ and is accessible for authorized users.

Jung-Min Koh and Bermseok Oh contributed equally to this work

J.-M. Koh · G.S. Kim · J.M. Hong · T.-H. Kim

E.K. Park $(\bowtie) \cdot$ S.-Y. Kim

Skeletal Diseases Genome Research Center, Kyungpook National

University Hospital, 44-2, Samduk 2-ga, Jung-gu,

700-412 Daegu, Republic of Korea

E-mail: epark@knu.ac.kr

Tel.: + 82-53-4205436

Fax: + 82-53-4205453

J.-M. Koh · G.S. Kim

Division of Endocrinology and Metabolism, University of Ulsan College of Medicine, Asan Medical Center, 138-736 Seoul,

Republic of Korea

B. Oh $\cdot$ J.Y. Lee $\cdot$ J.-K. Lee $\cdot$ K. Kimm

National Genome Research Institute, National Institute of Health,

5 Nokbun-Dong, Eunpyung-Ku, 122-701 Seoul, South Korea

B.L. Park · H.S. Cheong $\cdot$ H.D. Shin

Department of Genetic Epidemiology, SNP Genetics, 11th Floor, Maehun B/D, 13 Chongro 4 Ga, Chongro Gu, 110-834 Seoul, Republic of Korea

S.-Y. Kim $(\bowtie)$

Department of Orthopedic Surgery, Kyungpook National University School of Medicine, 50 Samduk 2-ga, Jung-gu, 700-712 Daegu, Republic of Korea

E-mail: syukim@knu.ac.kr

Tel.: + 82-53-4205635

Fax: + 82-53-4226605
Five polymorphisms $(+15667 \mathrm{G}>\mathrm{A}, \quad+15775 \mathrm{C}>\mathrm{G}$, $+16285 \mathrm{C}>\mathrm{T},+19317 \mathrm{C}>\mathrm{T},+22331 \mathrm{~A}>\mathrm{G})$ were selected and genotyped in postmenopausal Korean women $(n=560)$ together with measurement of the areal BMD $\left(\mathrm{g} / \mathrm{cm}^{2}\right)$ of the anterior-posterior lumbar spine and the non-dominant proximal femur using dual-energy X-ray absorptiometry. We found that polymorphisms of the SEMA7A gene were associated with the BMD of the lumbar spine and femoral neck. $S E M A 7 A+15775 C>G$ and $S E M A 7 A+22331 A>G$ were associated with low BMD of the femoral neck $(P=0.02)$ and lumbar spine $(P=0.04)$ in a recessive model. SEMA7A-ht4 also showed an association with risk of vertebral fracture $(\mathrm{OR}=1.87-1.93, P=0.02-0.03)$. Our results suggest that variations in $S E M A 7 A$ may play a role in decreased BMD and risk of vertebral fracture.

Keywords BMD $\cdot S E M A 7 A \cdot$ Fracture

Polymorphism $\cdot$ Postmenopausal women

\section{Introduction}

Osteoporosis is a systemic bone disease characterized by low bone mineral density (BMD) and increased risk of fracture (Peacock et al. 2002). Although multiple risk factors influence BMD and thus the pathogenesis of osteoporosis, genetic factors are mainly implicated, accounting for about $50-85 \%$ of the variance in BMD based on twin and family studies (Slemenda et al. 1991; Kanis et al. 1994; Lander and Schork 1994; Weeks and Lathrop 1995; Arden and Spector 1997; Eisman 1999; Stewart and Ralston 2000). In a pathological condition, an imbalance of bone remodeling occurs due to the increased rate of bone resorption by osteoclasts over the rate of bone formation by osteoblasts. Therefore, genes involved in osteoclast differentiation and function are potential candidate genes for having a genetic effect on BMD and osteoporosis.

Semaphorin 7A (SEMA7A), located on chromosome $15 \mathrm{q} 22.3-\mathrm{q} 23$, has been implicated in the regulation of the 
immune and nervous systems (Comeau et al. 1998; Lange et al. 1998; Xu et al. 1998; Pasterkamp et al. 2003). SEMA7A is a cell surface protein associated through a glycophosphatidylinositol (GPI) linkage (Xu et al. 1998), and has been shown to be a potent activator of macrophages. SEMA7A induces chemotaxis, inflammatory cytokine production [interleukin-1 (IL-1 $\beta$ ), tumour necrosis factor- $\alpha$ (TNF- $\alpha$ ), IL-6 and IL-8] and superoxide release in monocytes whereas it does not influence cytokine production in B and T cells (Holmes et al. 2002). SEMA7A was also shown to induce the production of granulocyte-macrophage colony stimulating factor (GM-CSF) and the differentiation of monocytes into dendritic cells (Holmes et al. 2002). Recently it was shown that SEMA7A is capable of increasing the migration of MC3T3 cells and enhancing the fusion of osteoclasts (Delorme et al. 2005). These results suggest that SEMA7A plays a critical role in the differentiation and activation of myeloid cells such as macrophages and osteoclasts.

In the present study, we investigated the genetic effects of SEMA7A on the determination of bone mass by direct resequencing of the gene to detect polymorphisms, and by analyzing its association with BMD and fracture risk in postmenopausal Korean women.

\section{Materials and methods}

\section{Subjects}

The study population, comprising 560 postmenopausal women of Korean ethnicity who visited Asan Medical Center (AMC, Seoul, Korea), was previously reported (Kim et al. 2005). Menopause was defined as the absence of menstruation for at least 6 months, and was confirmed by measurement of serum follicle-stimulating hormone (FSH). Women with premature menopause (before 40 years of age) were excluded. Women who had taken drugs that might affect bone metabolism for more than 6 months or within the previous 12 months were also excluded. Subjects were excluded if they had suffered from any disease that might affect bone metabolism. Women who had had a stroke or dementia were also excluded because of concerns related to their limited physical activity. Women were also excluded if they had osteophyte formation above the fourth grade of the Nathan classification (Nathan 1962), and/or severe facet joint osteoarthritis in the lumbar spine diagnosed using conventional spine radiographs. The study was approved by the AMC ethics review committee and written informed consent was obtained from all subjects.

Areal BMD $\left(\mathrm{g} / \mathrm{cm}^{2}\right)$ of the anterior-posterior lumbar spine (L2-L4) and proximal femur (femoral neck, femoral shaft, total femur, trochanter and Ward's triangle) was measured using dual energy X-ray absorptiometry (Lunar Expert XL with software version 1.90; Madison, WI) in 431 women. In 129 women, BMD was measured using Hologic QDR 4500-A with software version 4.84 (Waltham, MA). The Hologic machine did not measure BMD at the femoral shaft, thus BMD values were measured only at the lumbar spine and femoral neck before January 2001 in our institution, i.e., BMD values at the femoral shaft and at other proximal femur sites (total femur, trochanter and Ward's triangle) were not available in 229 and 100 subjects, respectively. Because of upper extremity dominance, the BMD at the proximal femur was measured at non-dominant sites. Short-term in vivo measurement precision for the Lunar and Hologic machines, expressed as the coefficient of variation, were 0.82 and $0.85 \%$ for the lumbar spine, respectively, and 1.12 and $1.20 \%$ for the femoral neck, respectively. These values were obtained by scanning 17 volunteers who were not part of the study; each volunteer underwent five scans on the same day, getting on and off the table between examinations. To derive cross-calibration equations between the two systems, BMD values were measured at the lumbar and femoral neck by the two machines in 109 healthy Korean women $(55 \pm 11$ years, range $31-75$ years), and cross-calibration equations were calculated as follows (Jo et al. 1999):

$$
\begin{aligned}
& \text { L2 }- \text { L4 BMD }\left(\mathrm{g} / \mathrm{cm}^{2}\right) \text { : Lunar }=1.1287 \times \text { Hologic } \\
& \quad-0.0027 \\
& \text { Femoral neck BMD }\left(\mathrm{g} / \mathrm{cm}^{2}\right): \text { Lunar }=1.1556 \\
& \times \text { Hologic }+0.0182
\end{aligned}
$$

The T-score was used to diagnose osteopenia and osteoporosis at each site according to the World Health Organization (WHO) definition $(-2.5<\mathrm{T}$ score $<-1.0 \mathrm{SD}$ and $\mathrm{T}$-score $\leq-2.5 \mathrm{SD}$, respectively); subjects having a $\mathrm{T}$-score over -1.0 were classified as normal controls. Lateral thoracolumbar (T4-L4) radiographs were obtained for all subjects. A vertebral fracture was defined quantitatively as a loss of $15 \%$ or more in the anterior, posterior, or middle height of one or more vertebral sites in subjects without previous history of major trauma such as traffic accident.

\section{Sequencing analysis of the $S E M A 7 A$ gene}

Genomic DNA was extracted from peripheral blood leukocytes using a commercial kit (Wizard Genomic DNA purification kit; Promega, Madison, WI). We sequenced exons and their boundaries of the SEMA7A gene, including the promoter region $(\sim 1.5 \mathrm{~kb})$, to discover genetic variants in 24 Korean DNA samples using a DNA analyzer (ABI PRISM 3700; Applied Biosystems, Foster City, CA). Fourteen primer sets for the SEMA7A gene for amplification and sequencing analysis were designed based on GenBank sequences (reference genomic sequence for SEMA7A: accession number NM_003612). Information regarding the primers used is available on our website; sequence variants were verified by chromatograms (http://www.snpgenetics.com/reference/SEMA7A_add_info.doc). 
Table 1 Clinical profiles and multiple regression analyses on bone mineral density (BMD) $\left(\mathrm{g} / \mathrm{cm}^{2}\right)$ in postmenopausal Korean women $(n=560)$. YSM Years since menopause

\begin{tabular}{|c|c|c|c|c|c|c|c|}
\hline \multicolumn{2}{|c|}{ Clinical profiles } & \multicolumn{3}{|l|}{ Spine BMD } & \multicolumn{3}{|l|}{ Femoral neck BMD } \\
\hline Weight (kg) & $56.5( \pm 7.4)$ & 0.006 & 0.001 & $<0.0001$ & 0.003 & 0.001 & $<0.001$ \\
\hline Height $(\mathrm{cm})$ & $154.8( \pm 5.3)$ & 0.003 & 0.001 & 0.013 & 0.002 & 0.001 & 0.0911 \\
\hline YSM (years) & $10.4( \pm 8.2)$ & $\begin{array}{l}-0.003 \\
\text { Final adjusted } R^{2}=0.254\end{array}$ & 0.002 & 0.02 & $\begin{array}{l}-0.005 \\
\text { Final adjusted } R^{2}=0.342\end{array}$ & 0.001 & $<0.0001$ \\
\hline
\end{tabular}

Genotyping using fluorescence polarization detection

For genotyping of polymorphic sites, amplifying primers and probes were designed for TaqMan (Livak 1999). Primer Express (Applied Biosystems) was used to design both the PCR primers and the MGB TaqMan probes. One allelic probe was labeled with FAM dye and the other with the fluorescent dye VIC. PCR was performed using TaqMan Universal Master mix without UNG (Applied Biosystems), with PCR primer concentrations of $900 \mathrm{nM}$ and TaqMan MGB-probe concentrations of $200 \mathrm{nM}$. Reactions were performed in a 384-well format in a total reaction volume of $5 \mu \mathrm{l}$ using $20 \mathrm{ng}$ genomic DNA. The plates then were placed in a thermal cycler (PE 9700, Applied Biosystems) and heated at $50^{\circ} \mathrm{C}$ for $2 \mathrm{~min}$ and $95^{\circ} \mathrm{C}$ for $10 \mathrm{~min}$, followed by 40 cycles of $95^{\circ} \mathrm{C}$ for $15 \mathrm{~s}$ and $60^{\circ} \mathrm{C}$ for $1 \mathrm{~min}$. The TaqMan assay plates were transferred to a Prism 7900HT instrument (Applied Biosystems) where the fluorescence intensity in each well of the plate was read. Fluorescence data files from each plate were analyzed using automated software (SDS 2.1, Applied Biosystems). Information regarding the primers is available on our website (http://www. snp-genetics.com/reference/SEMA7A_add_info.doc).

\section{Statistics}

To determine whether individual variants were in equilibrium at each locus in the population (Hardy-Weinberg equilibrium), $\chi^{2}$ tests were applied. We examined Lewontin's $D^{\prime}\left(\left|D^{\prime}\right|\right)$ and the linkage disequilibrium (LD) coefficient, $r^{2}$, between all pairs of biallelic loci (Hedrick 1987; Hedrick and Kumar 2001). Haplotypes (ht) of each individual were inferred using the algorithm developed by Stephens et al. (2001) (PHASE), which uses a Bayesian approach incorporating a priori expectations of haplotypic structure based on population genetics and coalescent theory. Phase probabilities of all polymorphic sites for haplotypes were calculated for each individual by this software. Individuals with phase probabilities less than $97 \%$ were excluded from the analysis. The genetic effects of inferred haplotypes were analyzed in the same way as polymorphisms. Multiple regression analyses were performed for BMD, controlling for age (continuous variable), years since menopause (YSM; continuous variable), weight, height, and type of evaluation machine as covariants. The genotype distributions of $S E M A 7 A$ polymorphisms and haplotypes between patient groups, including osteopenic and osteoporotic subjects and normal subjects, were analyzed with logistic regression models controlling for age, YSM, weight, height, and type of evaluation machine as covariants. In addition, genotype and haplotype distributions between patients with and without vertebral fractures were also analyzed with logistic regression model controlling for age, YSM, weight and height.

\section{Results and discussion}

The mean age of the participants was $59.4 \pm 7.2$ years (range 46-83 years), and the mean YSM was $10.4 \pm 8.2$ years (range $1-35$ years) (Table 1 ). As expected, age, weight, height, and YSM were significantly correlated with BMD at the lumbar spine and femoral neck, with the exception of the correlation between femoral neck BMD and height (Table 1). BMDs measured by Lunar equipment $(0.870 \pm 0.182$ and $0.723 \pm 0.128 \mathrm{~g} / \mathrm{cm}^{2}$ at the lumbar spine and femoral neck, respectively) were significantly higher than those measured by Hologic equipment $(0.764 \pm 0.116$ and $0.606 \pm 0.098 \mathrm{~g} / \mathrm{cm}^{2}$, respectively; $P<0.0001$ for both). Therefore, cross-calibration of BMD in the spine and femoral neck was carried out as described in Materials and methods.

Although SEMA7A has been implicated in the activation of monocytes/macrophages and in the induction of osteoclast fusion, no information about its genetic effects on human disease is available. To identify polymorphisms in $S E M A 7 A$, we directly sequenced all exons and their boundaries of the $S E M A 7 A$ gene, including $-1,500 \mathrm{bp}$ of the $5^{\prime}$ flanking region, and identified fifteen polymorphisms (one in the $5^{\prime}$ flanking region, eight in exons and six in introns) in a Korean population. Of the 15 polymorphisms identified, $6 \quad(-1396 \mathrm{~A}>\mathrm{G}$, $+15667 \mathrm{G}>\mathrm{A}, \quad+15955 \mathrm{C}>\mathrm{T} \quad \mathrm{C} 126 \mathrm{C}, \quad+16412 \mathrm{C}>\mathrm{G}$, $+16855 \mathrm{C}>\mathrm{G}$, and $+18986 \mathrm{G}>\mathrm{A}$ V334I) were newly identified in this study; their frequencies are shown in Fig. 1a. Genotype distributions of all loci were in Hardy-Weinberg equilibrium $(P>0.05)$. We selected five polymorphisms $(+15667 \mathrm{G}>\mathrm{A}, \quad+15775 \mathrm{C}>\mathrm{G}$, 
a Map of SEMA7A (sema domain, immunoglobulin domain (Ig), and GPI membrane anchor, (semaphorin) 7A) on chromosome 15q22.3-q23 (240 kb)

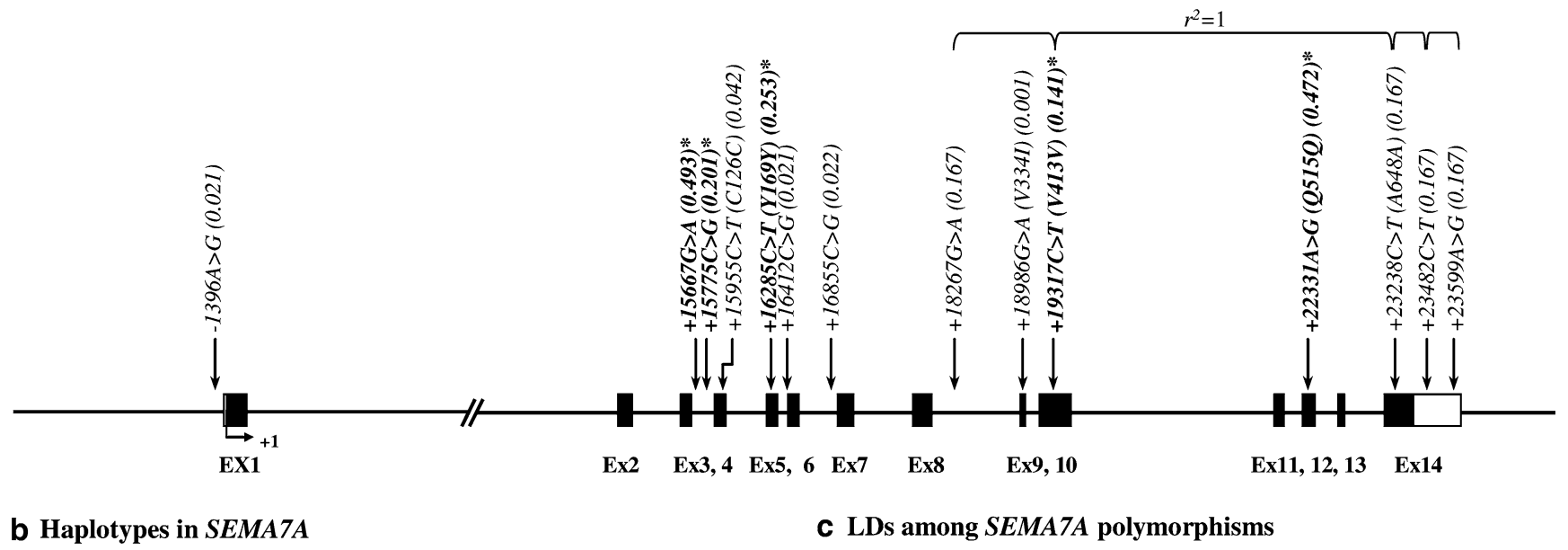

\begin{tabular}{|c|c|c|c|c|c|c|}
\hline Hap. & 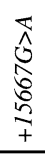 & $\begin{array}{l}0 \\
\hat{N} \\
\stackrel{n}{\hat{N}} \\
\hat{n} \\
+\end{array}$ & $\begin{array}{l}\hat{N} \\
0 \\
0 \\
0 \\
\mathbb{1} \\
+ \\
+\end{array}$ & $\begin{array}{l}\hat{n} \\
\hat{n} \\
\stackrel{2}{+} \\
+\end{array}$ & $\begin{array}{l}0 \\
\hat{\Lambda} \\
\approx \\
\approx \\
\tilde{N} \\
+\end{array}$ & Freq \\
\hline$h t 1$ & $\mathrm{G}$ & C & $\mathrm{C}$ & $\mathrm{C}$ & A & 0.376 \\
\hline$h t 2$ & A & G & C & C & G & 0.122 \\
\hline$h t 3$ & A & C & $\mathrm{T}$ & C & G & 0.117 \\
\hline$h t 4$ & A & C & $\mathrm{T}$ & $\mathrm{T}$ & G & 0.115 \\
\hline$h t 5$ & $\mathrm{G}$ & C & $\mathrm{C}$ & $\mathrm{C}$ & G & 0.080 \\
\hline$h+6$ & A & G & $\mathrm{C}$ & $\mathrm{C}$ & A & 0.057 \\
\hline$h t 7$ & A & C & $\mathrm{C}$ & $\mathrm{C}$ & $\mathrm{G}$ & 0.050 \\
\hline$h t 8$ & A & C & C & $\mathrm{T}$ & G & 0.020 \\
\hline$h t 9$ & $\mathrm{G}$ & G & $\mathrm{C}$ & C & A & 0.014 \\
\hline$h t 10$ & $\mathrm{G}$ & C & $\mathrm{T}$ & C & A & 0.011 \\
\hline$h t 11$ & A & C & $\mathrm{C}$ & C & A & 0.011 \\
\hline Other* & & & & & & 0.027 \\
\hline
\end{tabular}

Fig. 1a-c Gene maps and haplotypes of SEMA7A. Black blocks Coding exons; white blocks $5^{\prime}$ and $3^{\prime}$ UTRs, +1 first base of translation start site; asterisks polymorphisms genotyped in a larger population $(n=557)$. The frequencies of polymorphisms not subjected to larger scale genotyping were based on sequence data $(n=24)$. a Polymorphisms identified in $S E M A 7 A$ on chromosome

$+16285 \mathrm{C}>\mathrm{T},+19317 \mathrm{C}>\mathrm{T}$, and $+22331 \mathrm{~A}>\mathrm{G}$ ) for a larger scale genotyping $(n=560)$ by considering their position, allele frequencies, haplotype-tagging status, and LD coefficients among polymorphisms. SEMA7A gene haplotypes were constructed using PHASE software (Stephens et al. 2001) (Fig. 1b).

Using multiple regression analysis for association of BMD with lumbar spine, femoral neck and other bone sites, controlling for age, YSM, height, weight, and evaluation machines as covariants, SEMA7A+ $22331 A>G$ and $S E M A 7 A+15775 C>G$ were associated with low BMD of lumbar spine $(P=0.04)$ and femoral neck $(P=0.02)$, respectively (Table 2$)$. The BMD levels of lumbar spine (L2-L4) in individuals bearing minor homozygous genotype $[0.85 \pm 0.16 \quad(\mathrm{G} / \mathrm{G}$ of $+22331 A>G)$ ] were lower than those in individuals bearing common homozygous and heterozygous genotypes $(0.88 \pm 0.17$ and $0.88 \pm 0.17$, respectively; $P=0.04$, Table 2). Similarly, BMD levels of the femoral neck in individuals bearing minor homozygous genotype

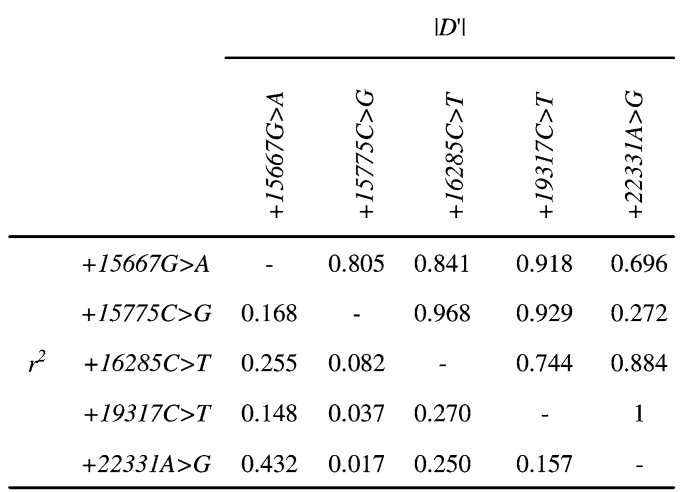

15q22.3-q23 (reference genome sequence: NT_010194). b Haplotypes of SEMA7A. Only those with frequencies over 0.01 are shown; others* includes rare haplotypes: GCTCG, GCCTG, GGCCG, ACTCA, and GGTCG. c Linkage disequilibrium (LD) coefficients $\left(\left|D^{\prime}\right|\right.$ and $\left.r^{2}\right)$ among $S E M A 7 A$ polymorphisms

$[0.68 \pm 0.13(\mathrm{G} / \mathrm{G}$ of $+15775 C>G)]$ were lower than those in individuals bearing common homozygous and heterozygous genotypes $(0.72 \pm 0.12$ and $0.73 \pm 0.12$, respectively; $P=0.02$, Table 2 ). Construction of haplotypes (Fig. 1b) and subsequent analysis revealed that SEMA7A-ht4 (ACTTG) was associated with susceptibility to risk of fracture $(\mathrm{OR}=1.87-1.93, P=0.02-0.03$; Table 3). The frequency of SEMA7A-ht4 was higher in the osteoporosis group than in that of the normal control. This haplotype included the $+22331 \mathrm{G}$ allele, which was associated with low BMD at the lumbar spine, suggesting that $S E M A 7 A+22331 A>G$ contributes to both low BMD at the lumbar spine and high risk of vertebral fracture.

Recently, SEMA7A was shown to increase the migration of MC3T3 osteoblasts and to enhance the fusion of osteoclasts (Delorme et al. 2005), suggesting a critical role in bone cells. Consistently, our association study of $S E M A 7 A$ polymorphism with BMD and risk of fracture demonstrates an association of SEMA7A 
Table 2 Regression analysis of BMDs of lumbar spine (L2-L4) and femoral neck in $S E M A 7 A$ polymorphisms after adjustment for age, YSM, weight, height, and bone densitometer. $C / C, C / R, R / R$ Homozygotes for the common allele, and heterozygotes and homozygotes for the rare allele, respectively, given as mean \pm standard deviation of BMD (number of subjects). $P$ values of codominant model for multiple regression analysis, controlling age, YSM, weight, height, and evaluation machine as covariants. $P_{\mathrm{a}}, P_{\mathrm{b}}$ and $P_{\mathrm{c}}$ were $P$ values of codominant, dominant and recessive models for multiple regression analysis, respectively

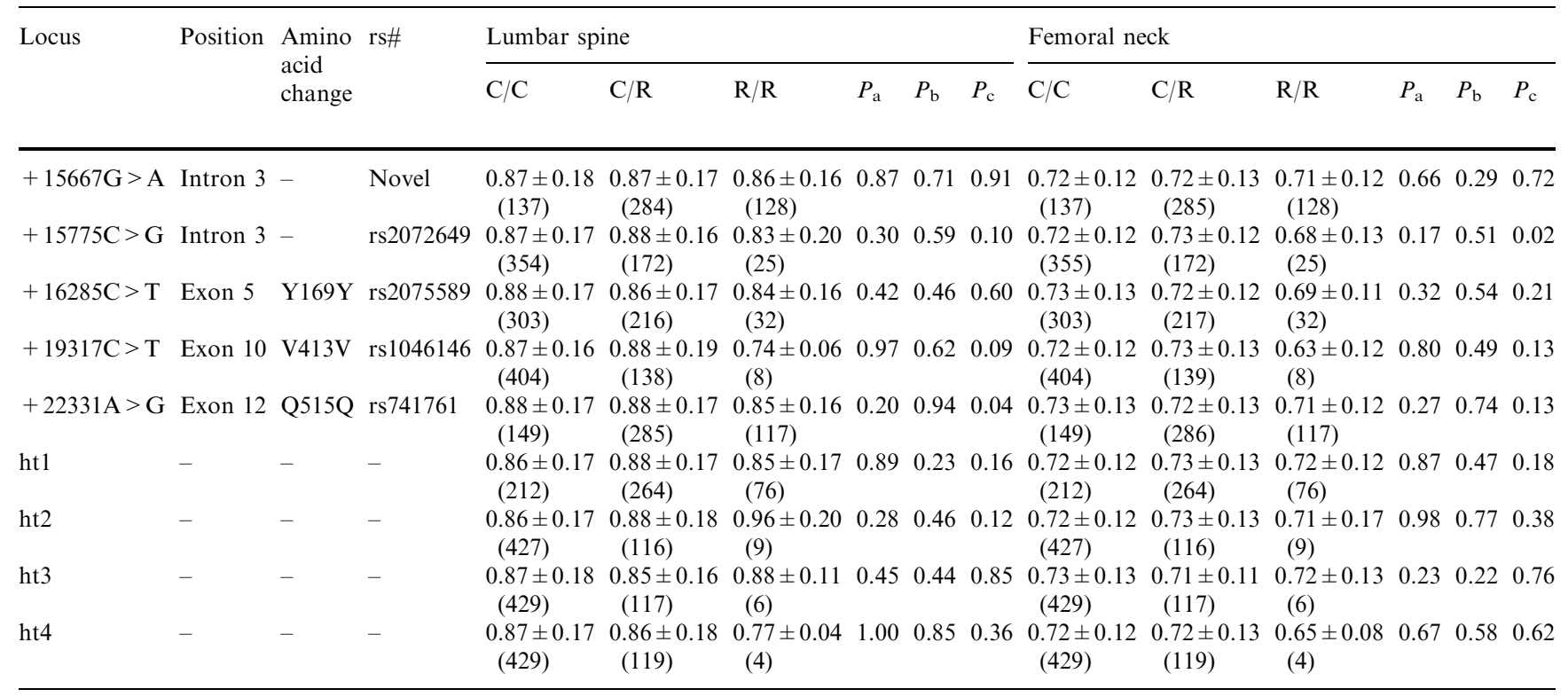

Table 3 Logistic analysis of SEMA7A polymorphisms with the risk of vertebral fracture - controlling for age, YSM, weight, height, and $\mathrm{BMD}$ of lumbar spine as covariants among a postmenopausal population

\begin{tabular}{|c|c|c|c|c|c|c|c|c|}
\hline Locus & Case $(n=91)$ & Control $(n=429)$ & \multicolumn{2}{|l|}{ Co-dominant } & \multicolumn{2}{|l|}{ Dominant } & \multicolumn{2}{|l|}{ Recessive } \\
\hline$+15775 \mathrm{C}>\mathrm{G}$ & 0.176 & 0.197 & $0.84(0.51-1.38)$ & 0.49 & $0.76(0.43-1.33)$ & 0.34 & $1.46(0.34-6.38)$ & 0.61 \\
\hline$+16285 \mathrm{C}>\mathrm{T}$ & 0.291 & 0.250 & $1.26(0.83-1.92)$ & 0.27 & $1.17(0.69-1.97)$ & 0.56 & $2.13(0.81-5.60)$ & 0.13 \\
\hline$+19317 \mathrm{C}>\mathrm{T}$ & 0.175 & 0.136 & $1.45(0.88-2.38)$ & 0.14 & $1.37(0.78-2.40)$ & 0.27 & $3.96(0.75-20.93)$ & 0.11 \\
\hline$+22331 \mathrm{~A}>\mathrm{G}$ & 0.524 & 0.468 & $1.26(0.87-1.84)$ & 0.23 & $1.25(0.69-2.28)$ & 0.47 & $1.48(0.80-2.72)$ & 0.21 \\
\hline ht3 & 0.110 & 0.121 & $0.82(0.46-1.47)$ & 0.51 & $0.86(0.46-1.59)$ & 0.62 & - & - \\
\hline ht4 & 0.181 & 0.104 & $1.93(1.13-3.28)$ & 0.02 & $1.87(1.05-3.32)$ & 0.03 & $8.76(0.78-98.10)$ & 0.08 \\
\hline
\end{tabular}

polymorphisms with low BMD of lumbar spine and femoral neck. SEMA7A-ht4 was also associated with high risk of vertebral fracture. To our knowledge, this is the first clinical report suggesting a role for SEMA7A in bone metabolism. Although the genetic effects of SEMA7A polymorphism on BMD and fracture risk are not dramatic, i.e., associated $P$-values did not retain significance after correction of multiple comparisons, it might be worthwhile to follow up on the signals of this important gene through larger cohort studies. Further biological and/or functional evidence would be needed to confirm the suggestive association of SEMA7A polymorphism with BMD.

In summary, to examine the possible involvement of genetic polymorphisms of $S E M A 7 A$ in osteoporosis, 15 polymorphisms in $S E M A 7 A$ were identified [nine known and six novel single nucleotide polymorphisms (SNPs)] and five SNPs were genotyped in postmenopausal Korean women $(n=560)$. Statistical analyses found genetic linkage of $S E M A 7 A+15775 C>G$ and $S E M A 7 A+22331 A>G$ with decreased BMD of spine and femoral neck as well as linkage of $S E M A 7 A-h t 4$ with risk of vertebral fracture in Korean postmenopausal women.

Acknowledgement This study was supported by a grant from the Korea Health 21 R\&D Project, Ministry of Health \& Welfare, Republic of Korea (Project No.: 01-PJ3-PG6-01GN11-0002).

\section{References}

Arden NK, Spector TD (1997) Genetic influences on muscle strength, lean body mass, and bone mineral density: a twin study. J Bone Miner Res 12:2076-2081 
Comeau MR, Johnson R, DuBose RF, Petersen M, Gearing P, VandenBos T, Park L, Farrah T, Buller RM, Cohen JI, Strockbine LD, Rauch C, Spriggs MK (1998) A poxvirus-encoded semaphorin induces cytokine production from monocytes and binds to a novel cellular semaphorin receptor, VESPR. Immunity 8:473-482

Delorme G, Saltel F, Bonnelye E, Jurdic P, Machuca-Gayet I (2005) Expression and function of semaphorin 7A in bone cells. Biol Cell 97:589-597

Eisman JA (1999) Genetics of osteoporosis. Endocr Rev 20:788-804

Hedrick P, Kumar S (2001) Mutation and linkage disequilibrium in human mtDNA. Eur J Hum Genet 9:969-972

Hedrick PW (1987) Gametic disequilibrium measures: proceed with caution. Genetics 117:331-341

Holmes S, Downs AM, Fosberry A, Hayes PD, Michalovich D, Murdoch P, Moores K, Fox J, Deen K, Pettman G, Wattam T, Lewis C (2002) Sema7A is a potent monocyte stimulator. Scand J Immunol 56:270-275

Jo JM, Kim JS, Kim GS, Kim SW, Shin JW, Moon DH, Lee HK (1999) Cross-calibration of bone mineral density between two different dual X-ray absorptiometry systems: hologic QDR 4500A and lunar EXPERT-XL. Korean J Nucl Med 33:282-288

Kanis JA, Melton LJ III, Christiansen C, Johnston CC, Khaltaev N (1994) The diagnosis of osteoporosis. J Bone Miner Res 9:1137-1141

Kim GS, Koh JM, Chang JS, Park BL, Kim LH, Park EK, Kim SY, Shin HD (2005) Association of the OSCAR promoter polymorphism with BMD in postmenopausal women. J Bone Miner Res 20:1342-1348

Lander ES, Schork NJ (1994) Genetic dissection of complex traits. Science 265:2037-2048
Lange C, Liehr T, Goen M, Gebhart E, Fleckenstein B, Ensser A (1998) New eukaryotic semaphorins with close homology to semaphorins of DNA viruses. Genomics 51:340-350

Livak KJ (1999) Allelic discrimination using fluorogenic probes and the $5^{\prime}$ nuclease assay. Genet Anal 14:143-149

Nathan H (1962) Osteophytes of the vertebral column: an anatomical study of their development according to age, race, and sex with considerations as to their etiology and significance. J Bone Joint Surg Am 44A:243-268

Pasterkamp RJ, Peschon JJ, Spriggs MK, Kolodkin AL (2003) Semaphorin 7A promotes axon outgrowth through integrins and MAPKs. Nature 424:398-405

Peacock M, Turner CH, Econs MJ, Foroud T (2002) Genetics of osteoporosis. Endocr Rev 23:303-326

Slemenda CW, Christian JC, Williams CJ, Norton JA, Johnston CC Jr (1991) Genetic determinants of bone mass in adult women: a reevaluation of the twin model and the potential importance of gene interaction on heritability estimates. J Bone Miner Res 6:561-567

Stephens M, Smith NJ, Donnelly P (2001) A new statistical method for haplotype reconstruction from population data. Am J Hum Genet 68:978-989

Stewart TL, Ralston SH (2000) Role of genetic factors in the pathogenesis of osteoporosis. J Endocrinol 166:235-245

Weeks DE, Lathrop GM (1995) Polygenic disease: methods for mapping complex disease traits. Trends Genet 11:513-519

Xu X, Ng S, Wu ZL, Nguyen D, Homburger S, Seidel-Dugan C, Ebens A, Luo Y (1998) Human semaphorin K1 is glycosylphosphatidylinositol-linked and defines a new subfamily of viral-related semaphorins. J Biol Chem 273:22428-22434 